\title{
Enzymatic Clipping of DNA Wires Coated with Magnetic Nanoparticles
}

Joseph M. Kinsella ${ }^{a}$ and Albena Ivanisevic ${ }^{*}$ a,

${ }^{a}$ Weldon School of Biomedical Engineering, ${ }^{b}$ Department of Chemistry, Purdue University, West Lafayette, IN 47907

Figure S1. The magnetic nanoparticles used in this study were synthesized using a method reported by Li et al., Chem. Mater., 2004, 16, 1391-1393. The scheme below is adapted from this reference. The nanoparticles were prepared by air-less thermal decomposition of $2.0 \mathrm{mmol} \mathrm{Fe}(\mathrm{acac})_{3}$ in $20 \mathrm{~mL}$ of 2-pyrrolidinone for $10 \mathrm{~min}$ and subsequently characterized.

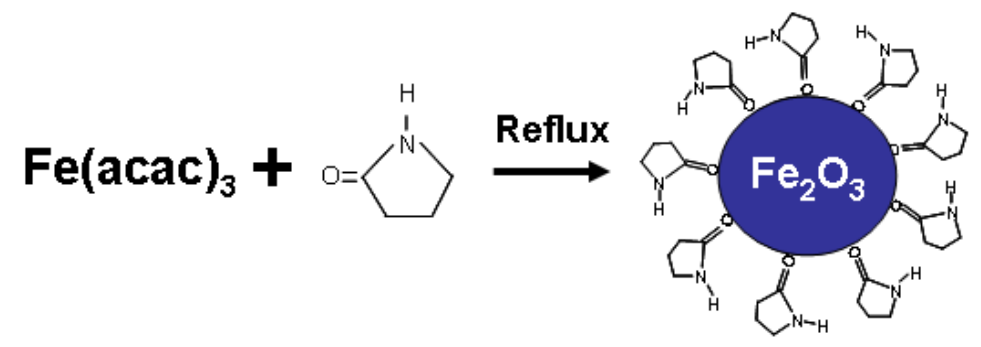

Figure S2. An XPS survey spectrum of the dried nanoparticles after they were cast on a $\mathrm{SiO}_{\mathrm{x}}$ surface. In addition to $\mathrm{Si}$, one can identify the presence of $\mathrm{C}, \mathrm{N}, \mathrm{O}$, and $\mathrm{Fe}$ on the surface.

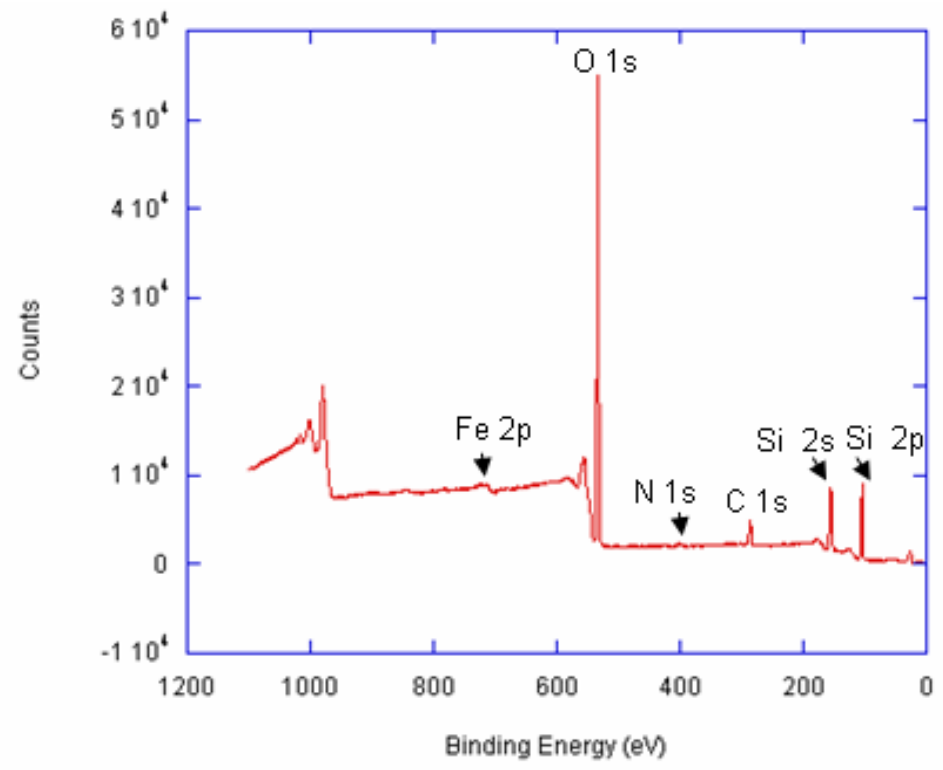


Figure S3. A high resolution XPS spectrum of the Fe 2p region of the dried nanoparticles.

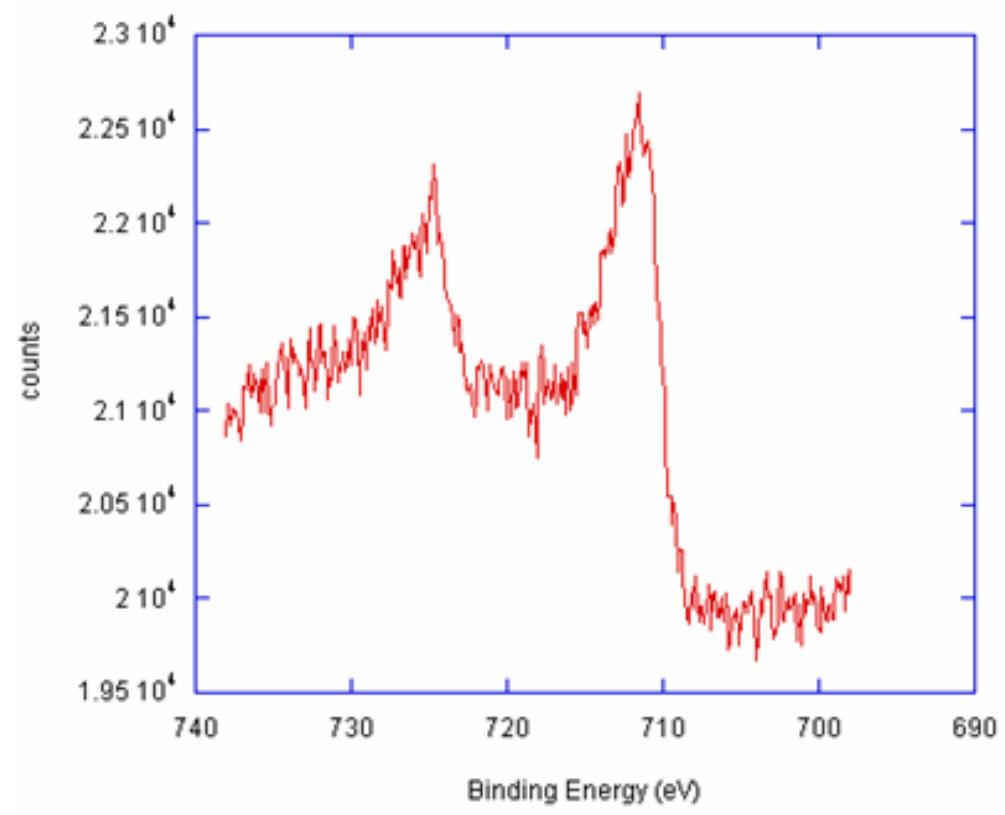

Figure S4. Powder X-ray diffraction data of the freshly synthesized nanoparticles.

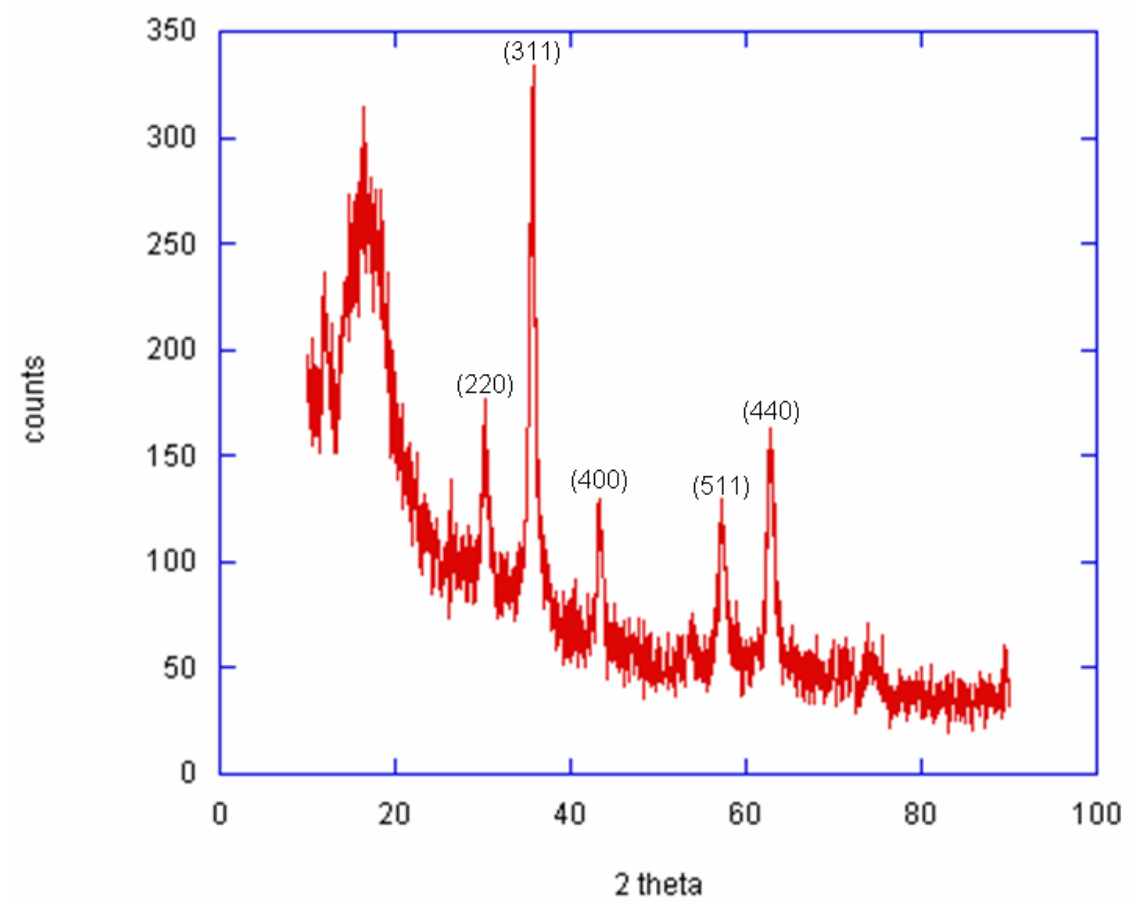


Figure S5. A TMAFM image of the dried magnetic nanoparticles.

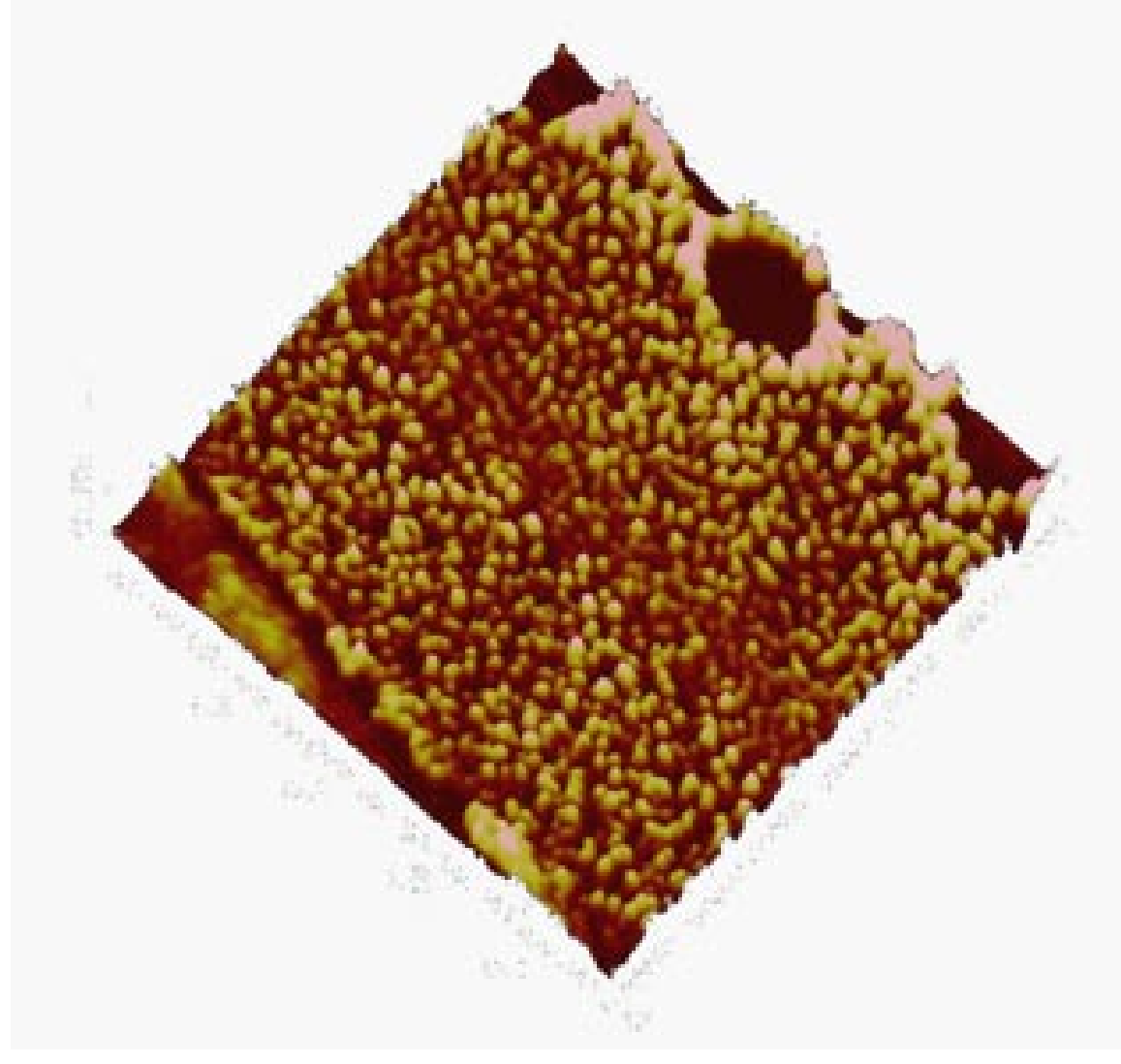

Figure S6. Nanoparticles size distribution. The average particle size is $4.10 .9 \mathrm{~nm}$ which was determined from analyzing 200 randomly imaged particles.

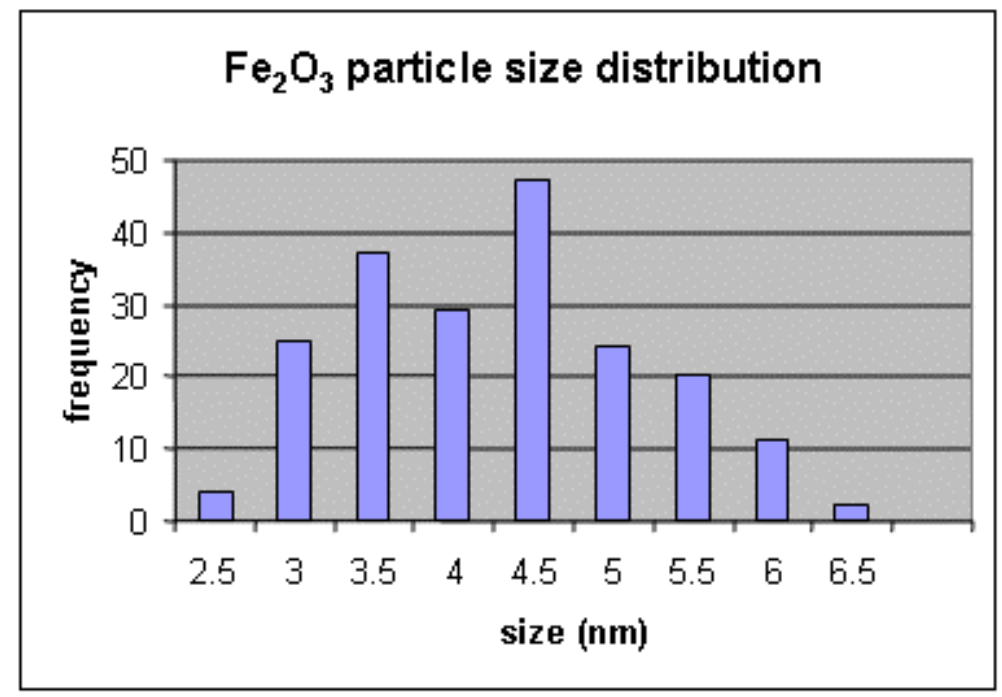


Figure S7. A TEM image of the nanoparticles used in this study.

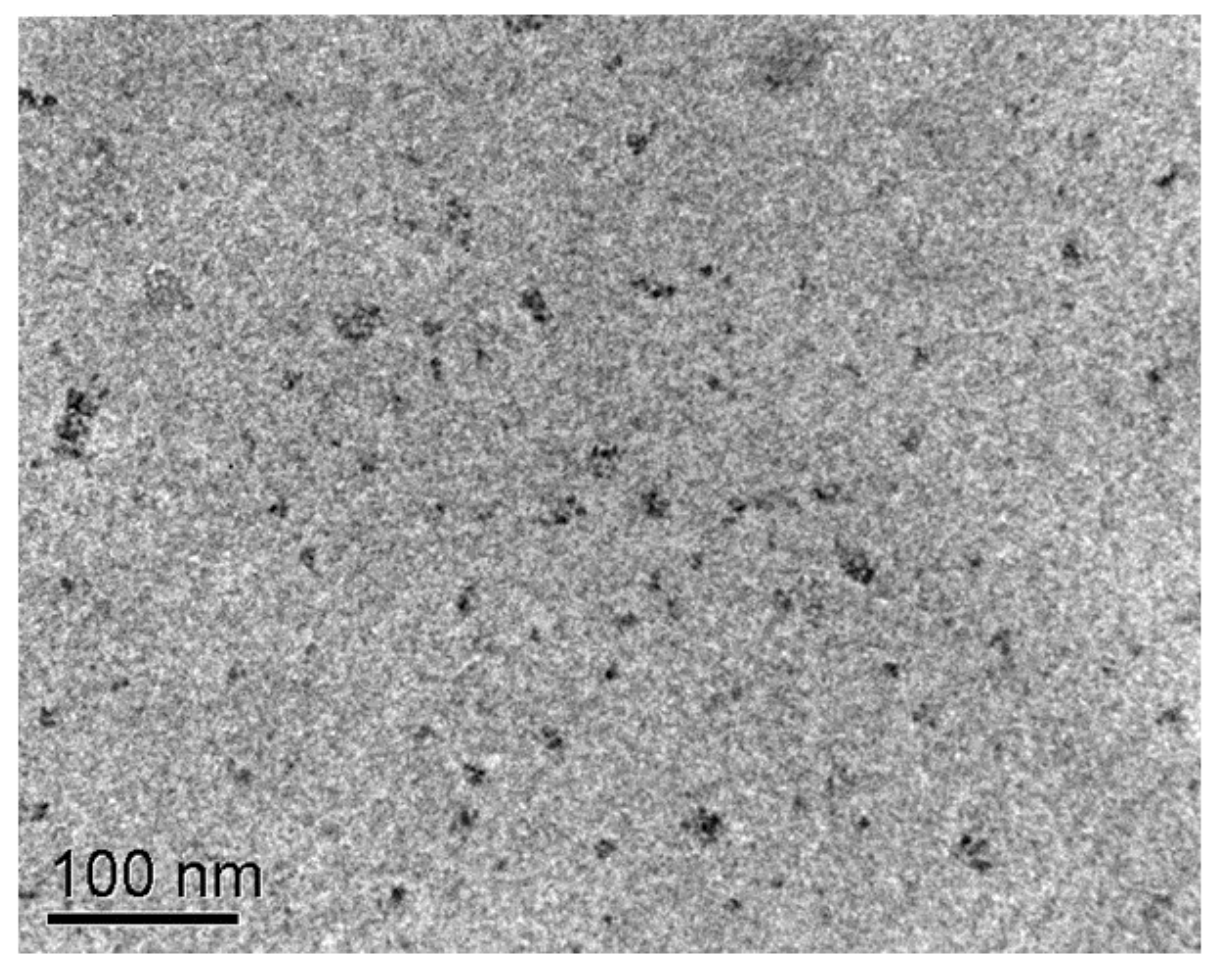

Figure S8. FT-IR data of the freshly synthesized $\mathrm{Fe}_{2} \mathrm{O}_{3}$ nanoparticles.

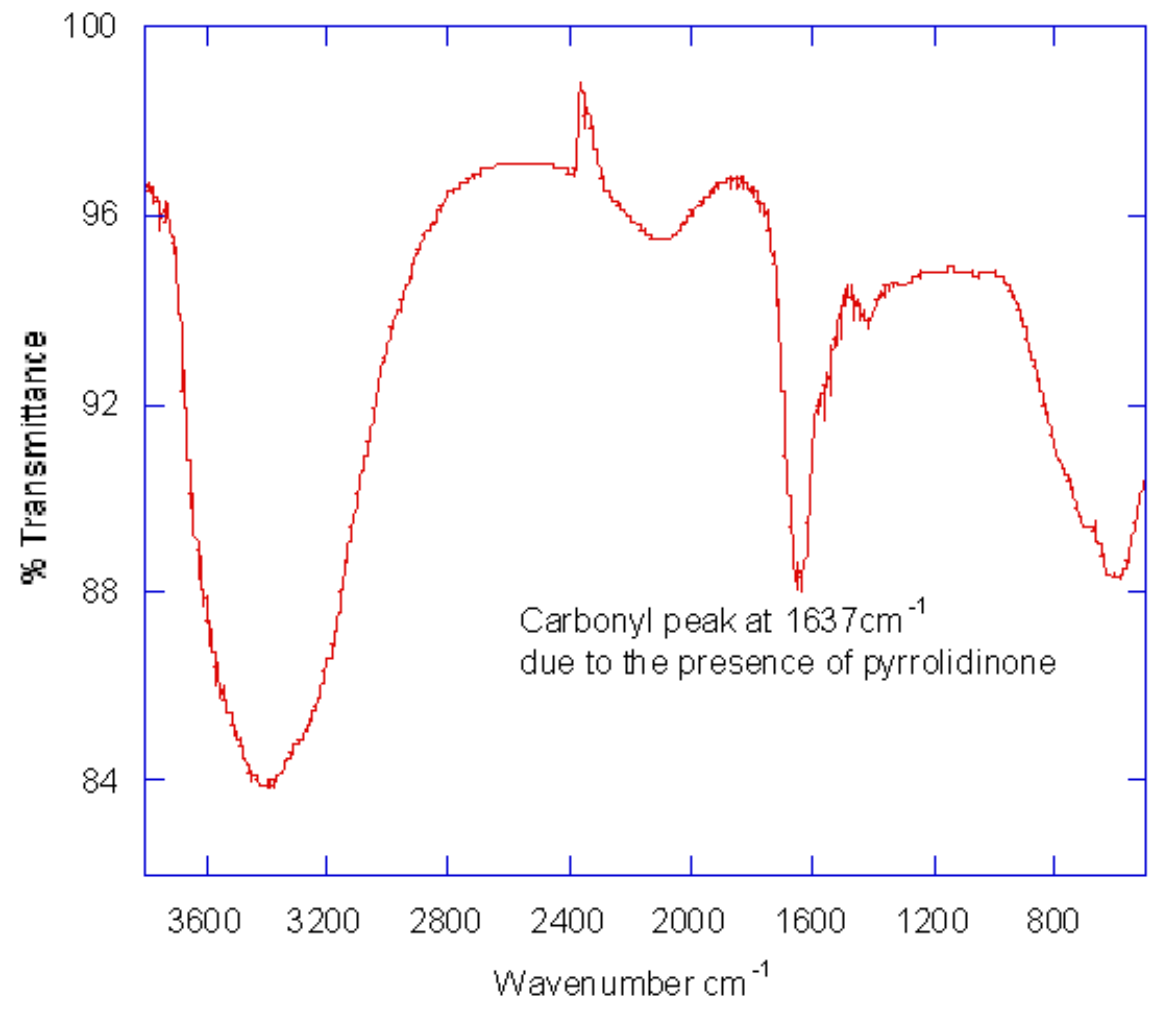


Figure S9. Tapping mode AFM height images of: a) bare DNA stretched by molecular combing on a modified SiOx surface. The line scan shows the height of the DNA to be $0.812 \mathrm{~nm}$; b) the same strand of DNA shown in a) after it was treated with BamH1. Arrows $1 \& 2$ indicate areas of the DNA that have been digested.
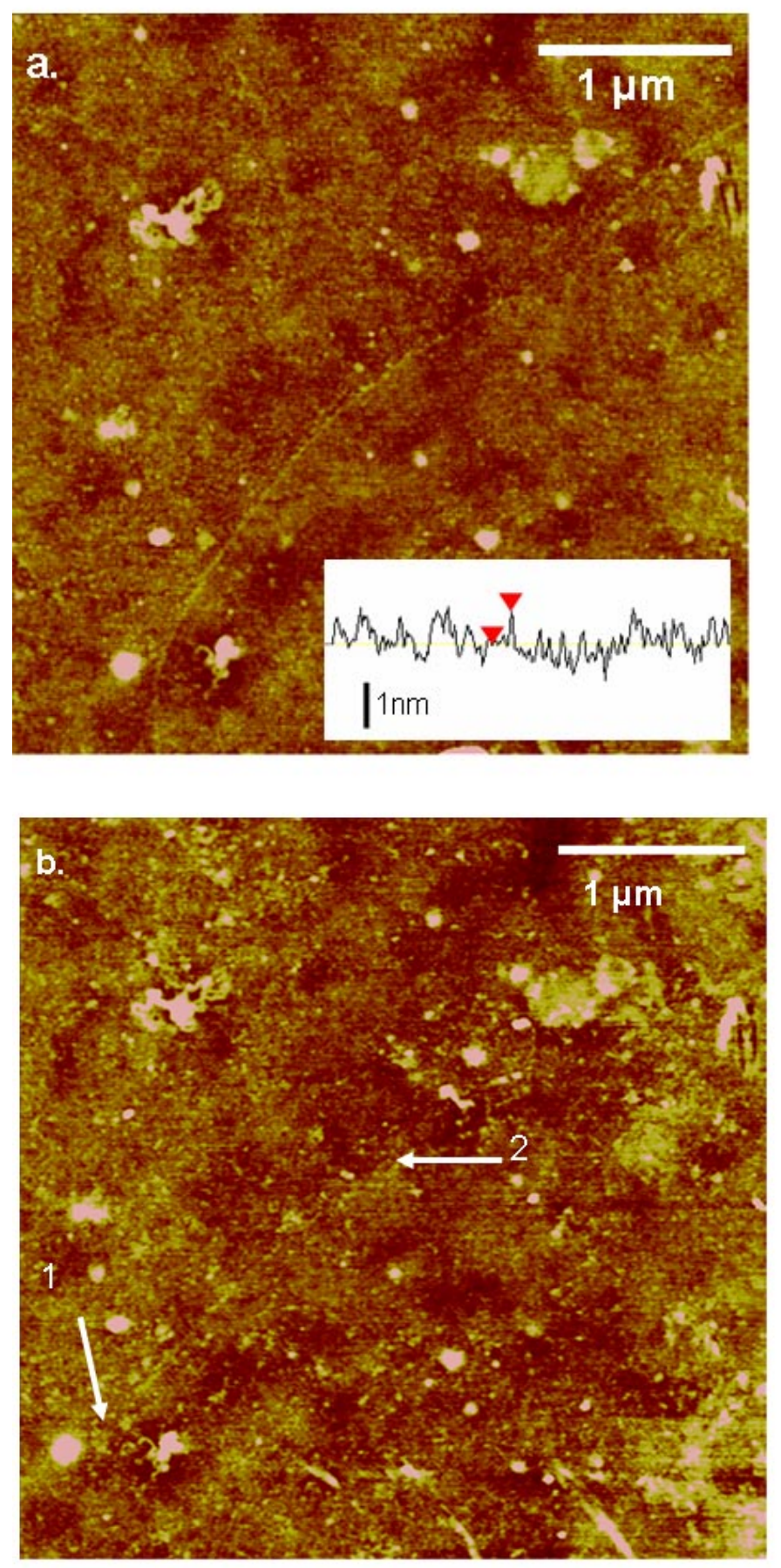
Figure S10. a) A templated DNA with $\mathrm{Fe}_{2} \mathrm{O}_{3}$ after it was stretched on a clean $\mathrm{SiOx}$ surface. The line scan inset shows the height of the templated DNA to be $1.462 \mathrm{~nm} ; \mathrm{b}$ ) The same strand of templated DNA shown in a) after it was treated with 10 units of BamH1.
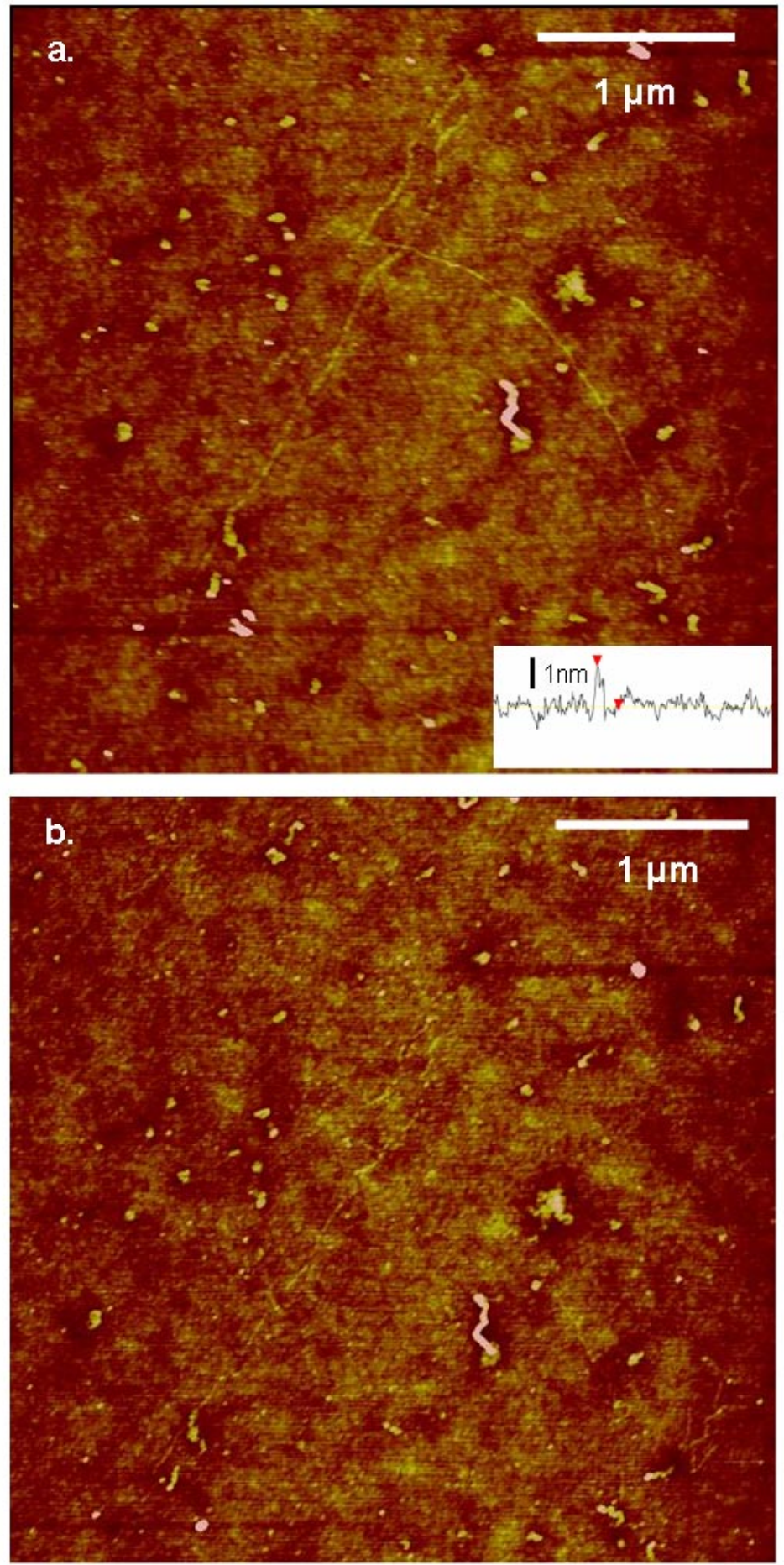
The enlarged figures shown in the text follow:

Figure 1.

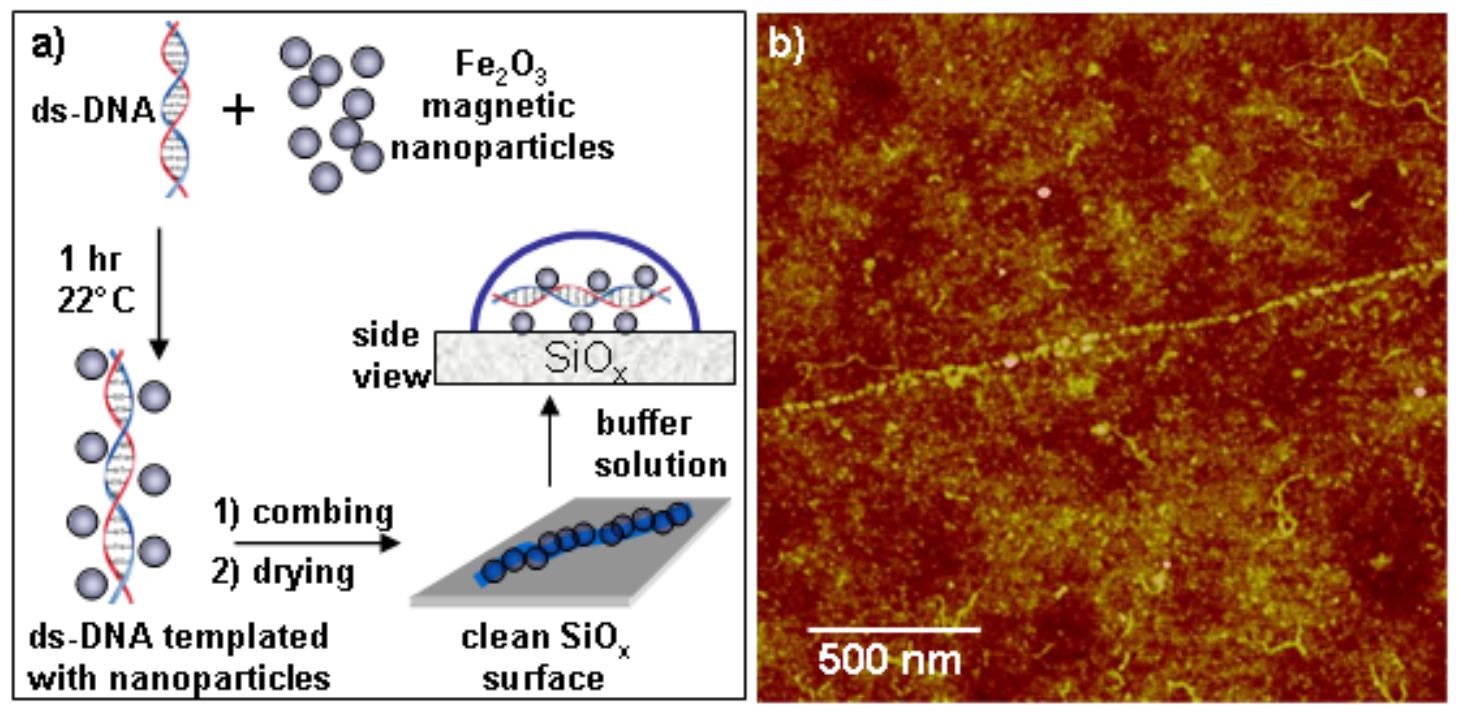

Figure 2a.

Gel 1
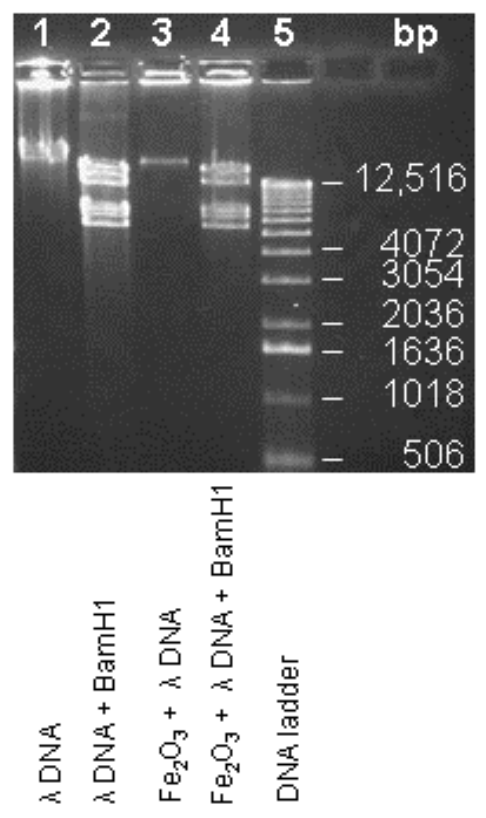

Gel 2

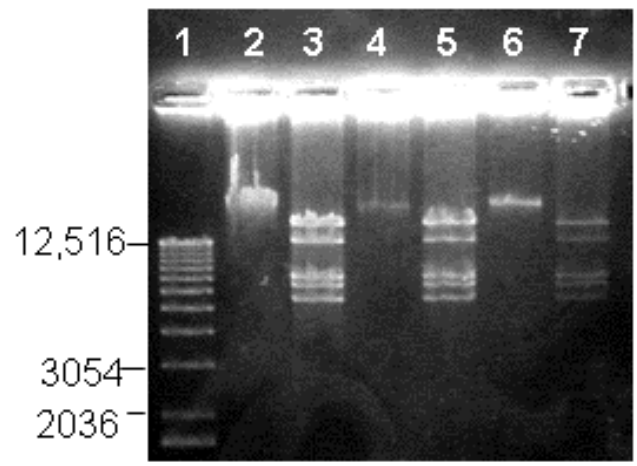

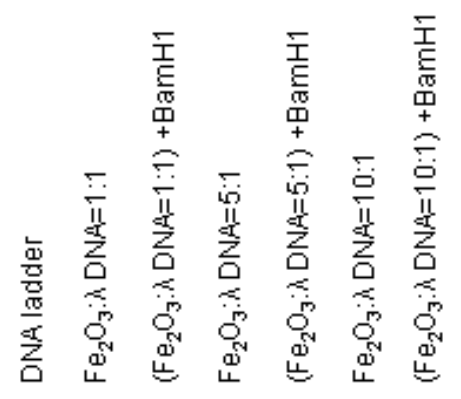




\section{Figure 2b.}

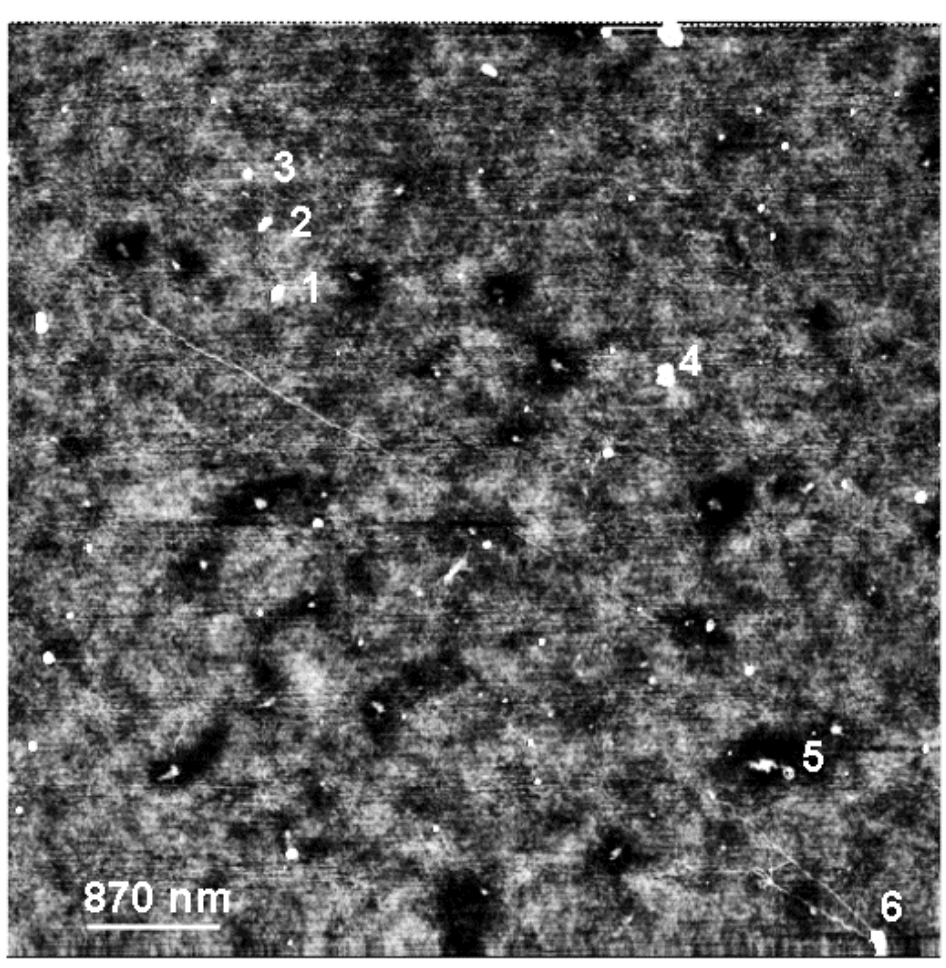

Figure 2c.

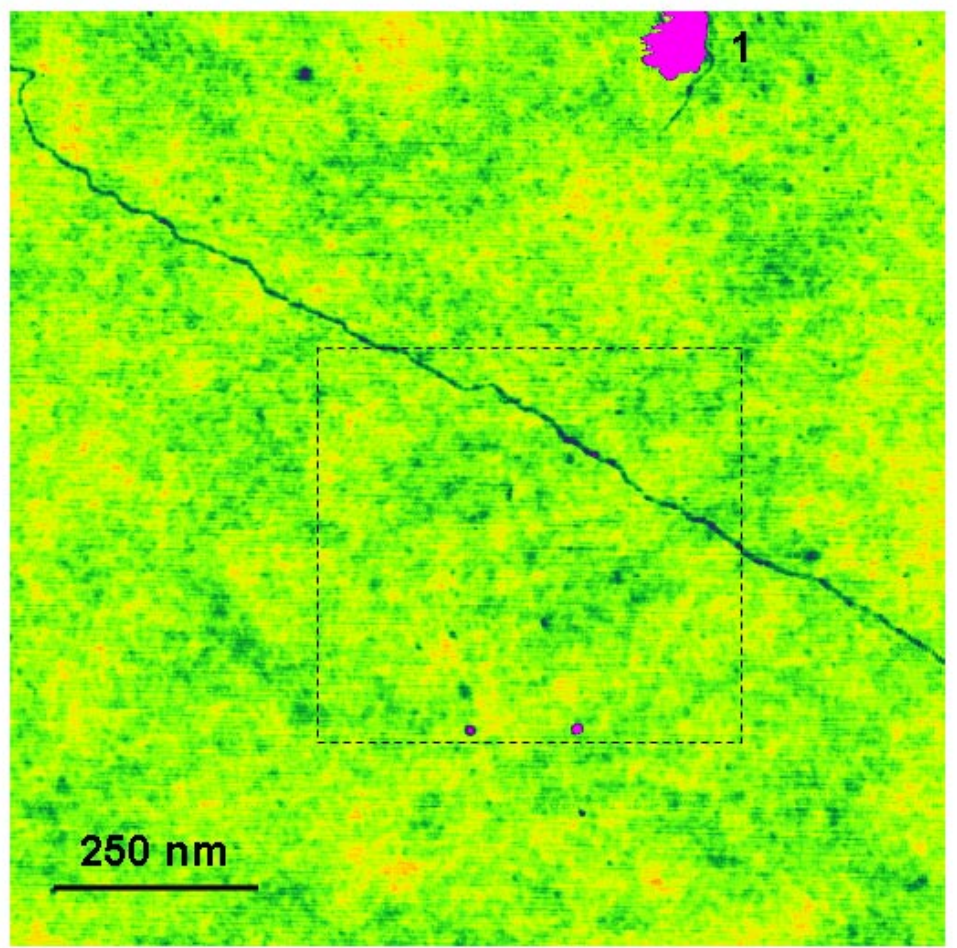


Figure 2d.

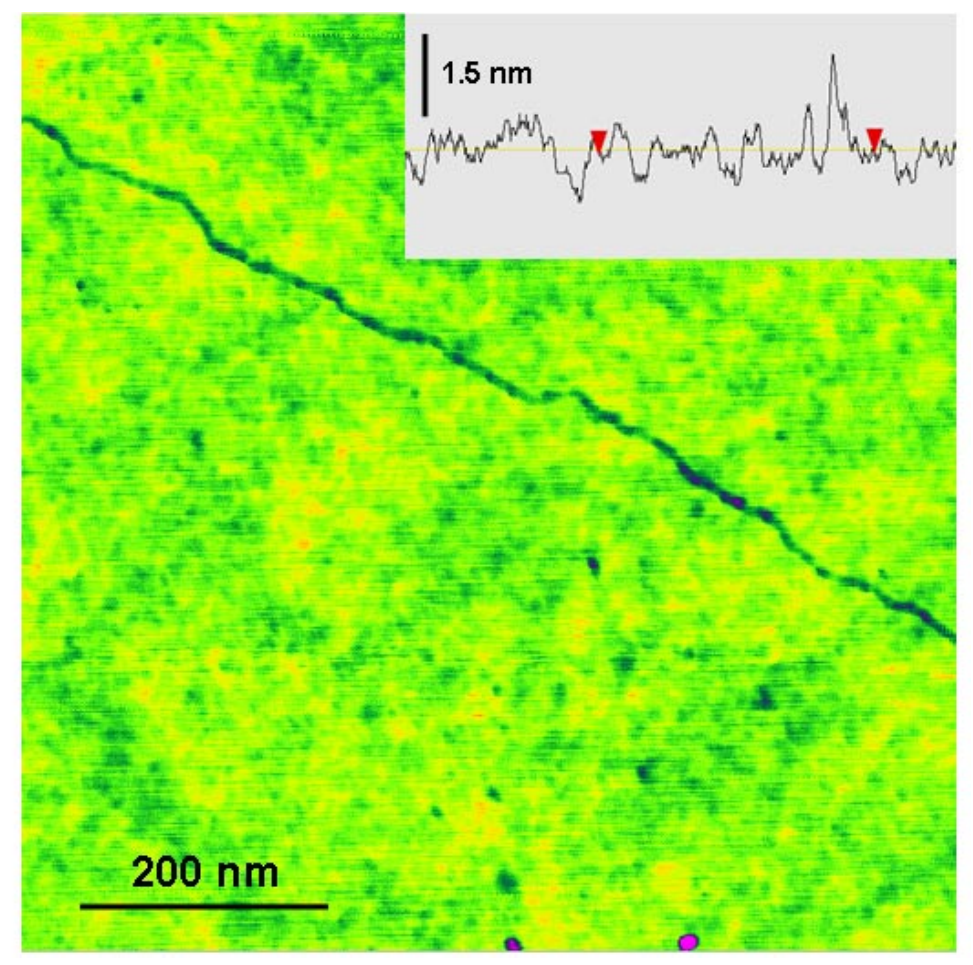

Figure 2e.

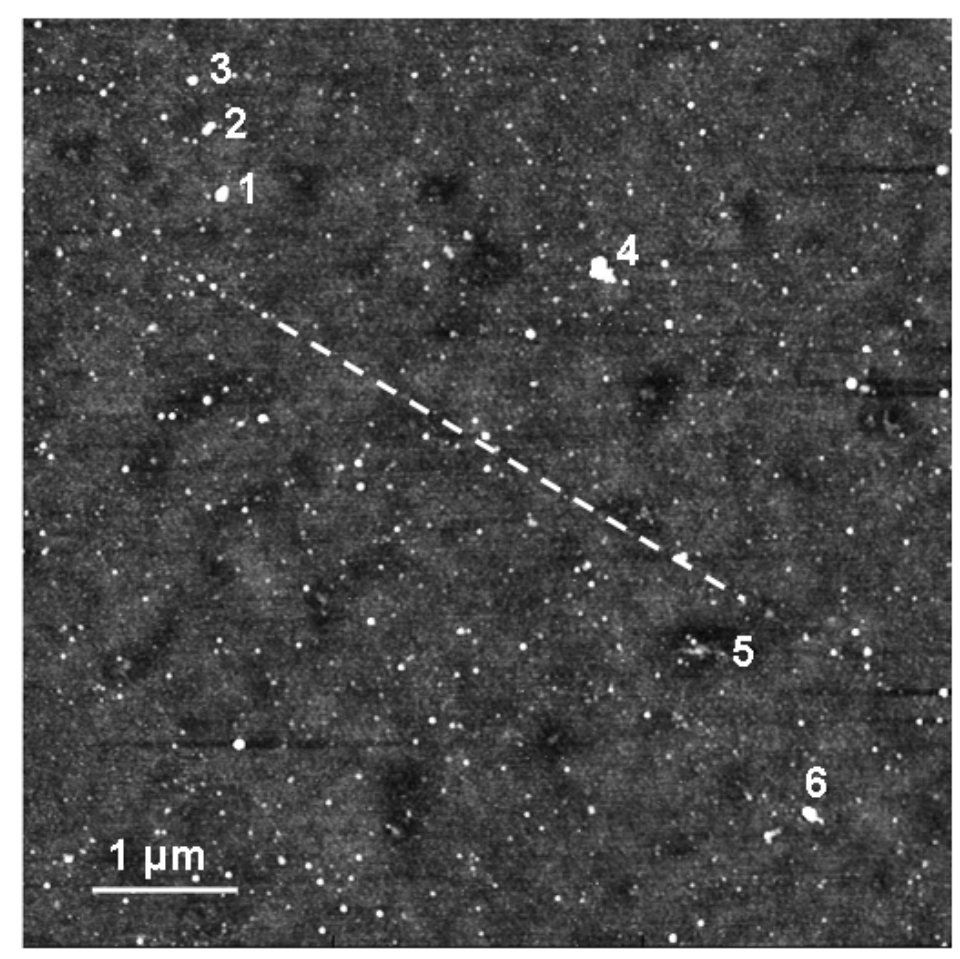


Figure 2f.

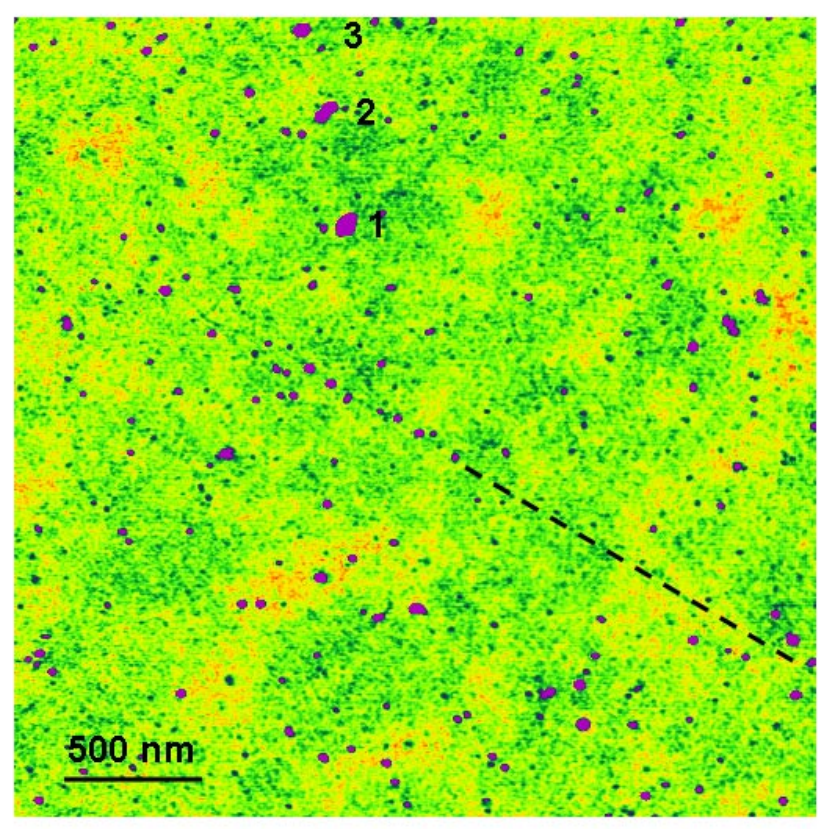

\section{Table of Contents Figure}

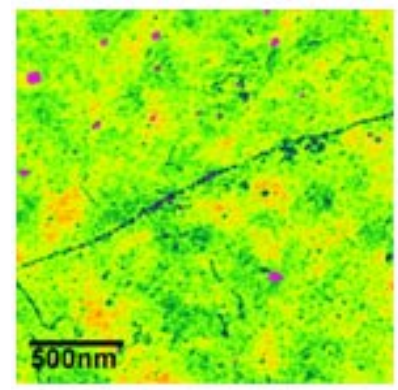

